\title{
TRANSFORMAÇÕES NA PRODUÇÃO DA PERIFERIA: O CASO DE ITAQUERA E O CONJUNTO HABITACIONAL JOSÉ BONIFÁCIO
}

\author{
Carolina Alvim de Oliveira Freitas* \\ * Universidade de São Paulo, Faculdade de Arquitetura e Urbanismo, São Paulo, SP, Brasil.
}

\begin{abstract}
Resumo
O artigo busca resgatar o processo de transformações socioespaciais na área que corresponde à Subprefeitura de Itaquera, na cidade de São Paulo, comparando sua centralidade (distrito de Itaquera) com o Conjunto Habitacional José Bonifácio (distrito de José Bonifácio). Para tanto, analisam-se dois ciclos da construção imobiliária: o período de 1970 a 1985, quando foi realizado o projeto dos conjuntos habitacionais do Banco Nacional de Desenvolvimento na região, por meio da Cohab-SP; e o de 2000 a 2015, intervalo em que foram implementadas infraestruturas, serviços e também investimentos imobiliários em razão da construção da Arena Corinthians no contexto da Copa do Mundo de Futebol. O intuito é demonstrar como o modelo centro-periferia, tradicional na interpretação sobre as cidades latino-americanas, não se aplica ao movimento de continuidades e descontinuidades da região em estudo.

Palavras-chave

Periferia; Metrópole; Espoliação; Fronteira.
\end{abstract}




\title{
TRANSFORMATIONS IN PRODUCTION OF PERIPHERY: THE CASE OF ITAQUERA AND THE JOSÉ BONIFÁCIO HOUSING ESTATE
}

\author{
Carolina Alvim de Oliveira Freitas* \\ * Universidade de São Paulo, Faculdade de Arquitetura e Urbanismo, São Paulo, SP, Brazil.
}

\begin{abstract}
The article seeks to rescue the process of socio-spatial transformations in the area that corresponds to the Subprefecture of Itaquera, in São Paulo city, comparing its centrality (district of Itaquera) with the one at José Bonifácio Housing Estate (district of José Bonifácio). For this purpose, two cycles of real estate construction are used: the period 1970-1985, when the housing project of the National Development Bank in the region was carried out, through CohabSP; and that from 2000 to 2015, interval in which infrastructure, services and real estate investments were implemented due to the construction of Arena Corinthians in the context of the Fifa World Cup. The aim is to demonstrate how the center-periphery model, traditional interpretation about Latin American cities, does not apply to the movement of continuities and discontinuities in the region under study.

Keywords

Periphery; Metropolis; Spoliation; Frontier.
\end{abstract}




\title{
TRANSFORMAÇÕES NA PRODUÇÃO DA PERIFERIA: O CASO DE ITAQUERA E O CONJUNTO HABITACIONAL JOSÉ BONIFÁCIO
}

\author{
Carolina Alvim de Oliveira Freitas
}

Introdução

O objetivo deste artigo é resgatar o processo de transformações socioespaciais em Itaquera, subprefeitura na zona leste de São Paulo, utilizando como referenciais temporais dois ciclos de investimentos na construção do espaço nessa região (aproximadamente, 1970-1985 e 2000-2015). A intenção é particularizar o Conjunto Habitacional José Bonifácio, o mais ao leste entre os quatro distritos que compõem essa subprefeitura, comparando seu processo localizado de transformações às mudanças no centro de Itaquera (Figura 1). Para tanto, são mobilizados dados oficiais da Prefeitura de São Paulo, pesquisas sobre a produção e a valorização imobiliária na região, entrevistas com moradores, além da investigação bibliográfica.

Por um lado, com a acelerada urbanização vivida na cidade de São Paulo no século XX, grande parte da classe trabalhadora localizada na zona leste vivenciou uma experiência de morar profundamente ligada ao padrão periférico de urbanização e, ao mesmo tempo, à degradação arquitetônica, a um residual modernista da construção habitacional de promoção estatal durante a vigência do Banco Nacional de Habitação (BNH), de 1964 a 1986, dominada pela técnica e pelo poder político-econômico. Por outro lado, essa forma habitacional passou por intensas transformações em sua consolidação, que transbordaram seu processo de homogeneização característico, inserido no contexto de produção industrial do espaço.

A ideia de transição dessa sociedade industrial para outra - a sociedade urbana, da maneira como Lefebvre propõe (1999; 2001) -, deve ser considerada à luz 
das categorias mais tradicionalmente utilizadas por pensadores na compreensão crítica das metrópoles latino-americanas: as noções de centro e periferia. Não são poucos os estudos urbanos brasileiros que, desde pelo menos a década de 1970, tocam nesse tema (SINGER, 1973; CAMARGO et al., 1975; MARICATO, 1979; KOWARICK, 2000), estabelecendo com ele o que seria a crítica da economia política do espaço. $O$ modelo explicativo que vigorou ao longo de décadas, no entanto, parece não mais servir para a compreensão de processos mais recentes de reestruturação imobiliária (PEREIRA, 2005).

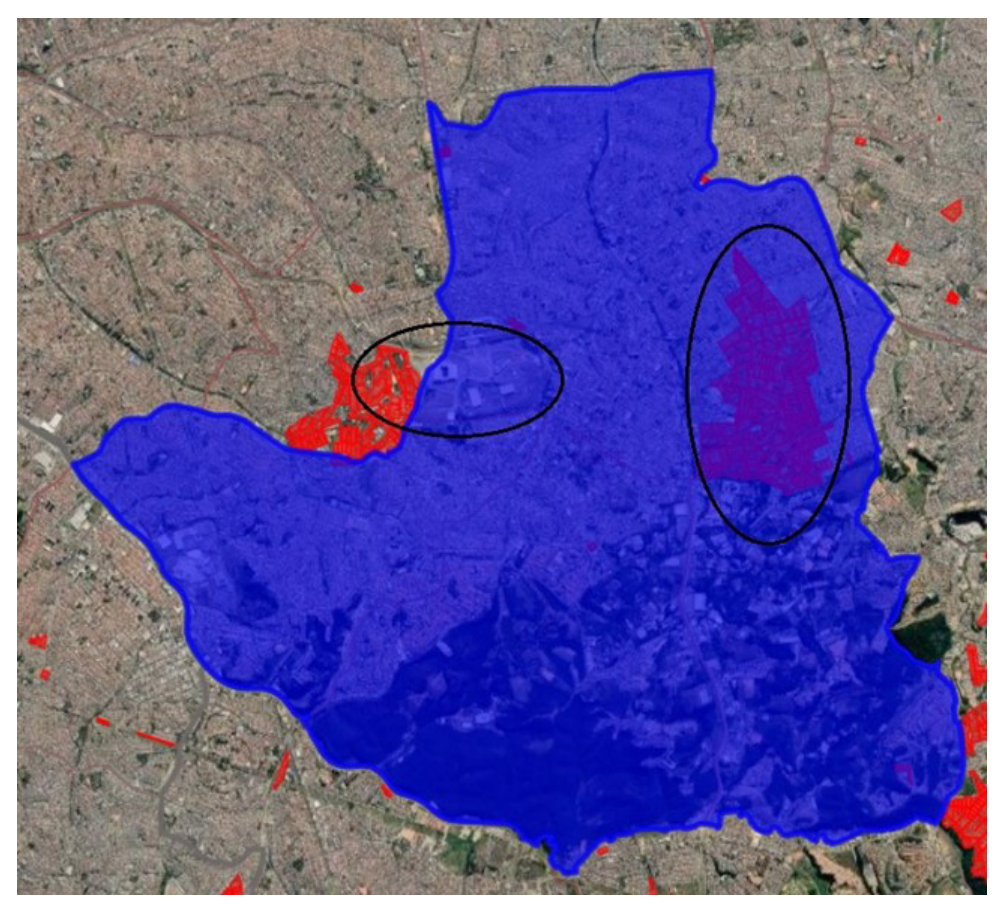

Figura 1. Subprefeitura de Itaquera.

Nota: Os círculos indicam a área onde foram construídos, à esquerda, a Arena Corinthians e o Polo Institucional do centro de Itaquera. Em vermelho, à direita, o Conjunto Habitacional José Bonifácio. Fonte: HabitaSampa. ${ }^{1}$

Nesse sentido, capturar o movimento dialético da relação entre centralidades e periferias ${ }^{2}$ se evidencia como necessidade metodológica na compreensão das

1. Disponível em: https://mapa.habitasampa.inf.br/. Acesso em: 10 ago. 2020.

2. Lefebvre apresenta a noção dialética de implosão-explosão para identificar o movimento de centralização e periferização da realidade urbana: “[...] a implosão-explosão (metáfora emprestada da física nuclear), ou seja, a enorme concentração (de pessoas, de atividades, de riquezas, de coisas e de objetos, de instrumentos, de meios e de pensamento) na realidade urbana, e a imensa explosão, a projeção de fragmentos múltiplos e disjuntos (periferias, subúrbios, residências secundárias, satélites etc.)" (LEFEBVRE, 1999, p. 23-24). 
transformações contemporâneas e de suas distinções em relação a outros ciclos intensivos e extensivos de produção do espaço do passado.

O centro, sob esse viés, não seria o marco geográfico zero de uma cidade ou metrópole, mas se trataria sobretudo de uma situação urbana na qual se concentram instituições, redes e trocas; a periferia, ao contrário, se constituiria como o espaço que nega o urbano às pessoas, sem ser necessariamente a margem em dada escala geográfica. Deste modo, centro e periferia podem ser concebidos como conceitos dialeticamente relacionais, como o movimento dinâmico de produção e reprodução do espaço, marcado pelo embaralhamento entre processos imediatos e globais.

Recentes investigações, críticas ao modelo tradicional de formalização da divisão da cidade entre centro e periferia, indicam a dinâmica de fragmentação como chave para a compreensão da produção urbana contemporânea, voltando-se aos novos projetos imobiliários e à aliança financeirizada entre Estado e mercado para apontar fenômenos de reestruturação imobiliária, como indica Pereira (2005). Como referência particular desses fenômenos de transição socioespacial de funções, formas e estruturas urbanas, próprios desse interstício entre os séculos XX e XXI, Itaquera vem sendo objeto de diversas pesquisas acadêmicas recentes.

Vale destacar, entretanto, que, se Itaquera adquiriu força como centralidade regional com base em projetos urbanos nas últimas décadas, certamente não exportou a mesma forma transformada do Conjunto Habitacional, hoje um complexo de propriedades condominiais. É preciso desvendar quais foram as mudanças, para além das aparências, na chamada "Cohab 2", que convergem e se diferenciam daquelas observadas na nova centralidade de Itaquera.

Dados oficiais e a pesquisa documental e bibliográfica permitem concluir que a região, que se manteve como área predominantemente rural até a metade do século passado, se tornou, a partir da década de 1970, alvo significativo da produção imobiliária e metropolitana, seguindo a tendência efetiva e mais ampla para a zona leste de São Paulo no período.

Três décadas depois, nos anos 2000, houve nova aceleração nas transformações, que aqui se apresenta como exemplar do reforço qualitativo dessa urbanização fragmentada na contemporaneidade. Identificando os índices de valorização e produção imobiliária, além do processo mais recente de construção da Arena Corinthians (atual Neo Química Arena) e de um Polo Institucional no centro de Itaquera, o que aqui se indaga é como esse processo se combina com a conceituação de periferia como a "fronteira de expansão do capital" do espaço metropolitano. Nos termos de Mautner (2010, p. 254): 
Consideramos periferia como base de um processo de produção de espaço urbano. A periferia é de fato um local onde vivem os pobres, é socialmente segregada, e o preço da terra é baixo, porém, ao mesmo tempo, é um local mutante, sempre reproduzindo em novas extensões de terra, enquanto velhas periferias são gradualmente incorporadas à cidade, ocupadas por novos moradores e reorganizadas pelo capital.

O espaço revestido da forma mercadoria se revela na combinação entre os planos de investimentos públicos e as apropriações privadas ao longo das décadas, bem como na construção de obras e edificações que produziram ali ciclos de valorização imobiliária (metrô, trem, conjuntos habitacionais, vias públicas e, mais tarde, shoppings, faculdades, hospitais, comércios, serviços, novos condomínios residenciais, estádio e projeto de polo institucional para desenvolvimento econômico).

Contudo, a incorporação de Itaquera à metrópole de São Paulo também é um processo notabilizado pela desintegração - uma presença frequentemente demarcada por ausências. Este artigo busca aspectos sobre como se dá o processo de consolidação dessa região periférica transformada que mantém sinais iminentes de urbanização precária, combinados com o seu desenvolvimento patrocinado pelas variadas concertações entre Estado e mercado.

A opção por nos atermos posteriormente à realidade do Conjunto Habitacional José Bonifácio objetiva contrapor duas velocidades e qualidades de mudanças no território que ocorreram em períodos históricos distintos. Enquanto o centro de Itaquera foi a "promessa da vez" (CUNHA, 2013) da produção imobiliária em São Paulo desde a preparação para a Copa do Mundo de Futebol em 2014, no Brasil, acompanhada de uma reestruturação espacial e de uma série de obras públicas projetadas e realizadas entre 2000 e 2015, José Bonifácio, referenciada como Itaquera II e III no projeto original da Cohab, é um exemplo da provisão estatal de habitação de quase quarenta anos de consolidação. Ainda considerada uma "cidade-dormitório", abrange, aproximadamente, 14 km² e 124 mil habitantes, os quais vivem, em grande maioria, nas edificações originais.

Além disso, importa para o trabalho como esses dois ciclos de investimentos - que aqui podem se demarcados, com aproximação, entre os anos de 1970 e 1985 e, depois, entre 2000 e 2015 - se relacionam, considerando as condições espaciais atuais da Cohab e suas determinações por essas novas entradas do capital imobiliário nos arredores e no próprio território circunscrito ao Conjunto.

\section{O Conjunto Habitacional José Bonifácio}

A área onde foi construído o Conjunto Habitacional José Bonifácio pertencia, desde 1966, ao Instituto Nacional de Previdência Social (INPS), instituição criada 
para unificar os antigos institutos de pensão e aposentadoria anteriores ao regime civil-militar. As áreas do antigo Instituto de Aposentadorias e Pensões dos Industriários (Iapi), que estavam ociosas, tornaram-se propriedade do BNH, que, por sua vez, as repassou à Companhia Metropolitana de Habitação de São Paulo (Cohab-SP).

Uma industrialização vigorosa era parte indispensável do projeto modernizador autoritário da ditadura civil-militar, correspondente a uma reorganização político-administrativa do Estado3 . A política habitacional dos anos 1970 é bastante exemplar, tanto da industrialização e do investimento em infraestrutura como do reforço do progresso enquanto conquista paternalista para o povo: "o sonho da casa própria” (BOLAFFI, 1982, p. 44).

Já no primeiro ano do golpe, 1964, foram criados o BNH e o Sistema Financeiro de Habitação (SFH), em um “casamento” histórico entre a indústria da construção, o mercado imobiliário e o capital financeiro (BOLAFFI, 1982; MARICATO, 1984), o que não teria sido possível se no período anterior não houvesse se concretizado um ciclo diversificado de industrialização no país, desde o Plano de Metas de Juscelino Kubitschek até 1961.

A Companhia Metropolitana de Habitação de São Paulo (Cohab), subordinada ao BNH, foi criada em 1965, com a missão de produzir habitação popular para famílias trabalhadoras de baixa renda que ganhassem até três salários mínimos. ${ }^{4}$ Sua atuação se concentrava na promoção da produção habitacional, definindo terrenos e projetos, chamando empreiteiras e construtoras para as licitações. Nunca na história do país haviam sido elaborados e executados projetos com a magnitude de escala e quantidade de unidades como aqueles que viriam a ser implementados na zona leste de São Paulo.

Entre 1967 e 1969, a Cohab comprou as terras onde mais tarde foi construído o Conjunto Itaquera I, no limite com a atual região de Arthur Alvim. As obras dos conjuntos habitacionais só foram iniciadas anos depois, já no fim da década de 1970. As obras da Cohab e do Metrô convergiram após uma decisão tomada no Ministério dos Transportes em 1974, que alterava o trajeto da linha leste-oeste do metrô, de modo que se estendesse do Tatuapé até Itaquera.

3. A ditadura civil-militar brasileira, entendida como ditadura de classes, complexificou a aliança entre 0 capital e o Estado, num contexto mais geral de alinhamento do Brasil ao capitalismo internacional. Isso significou, por um lado, um rearranjo na política econômica nacional, mais aberta e instrumentalizada à captura estrangeira, e, por outro, uma aparência propagandeada de modernização, sustentada pela ideologia do progresso.

4. O principal fundo orçamentário do BNH era o Fundo de Garantia do Tempo de Serviço (FGTS), instituído em 1966 por uma lei que decretava o fim da estabilidade decenal dos trabalhadores formais e permitia a transferência da riqueza parafiscal, diretamente associada ao trabalho, para setores privados da economia. 
Como afirma Ramalhoso (2013, p. 72-73): "Foi, portanto, em Itaquera que pela primeira e única vez as duas companhias atuaram concomitantemente como instrumentos da prefeitura para o desenvolvimento de uma área”. A articulação entre a Cohab e a empresa do metrô - na época dirigida mediante participação majoritária da prefeitura - foi decisiva historicamente para a transformação radical da região de Itaquera. O primeiro conjunto implantado foi inaugurado em 1978; dois anos depois, foram inaugurados Itaquera II e III, correspondentes ao grande Conjunto José Bonifácio.

Em 1979, foi inaugurada a linha leste-oeste e, apenas dez anos depois, em 1988, a ligação entre a Vila Matilde e Itaquera foi ativada e a estação terminal, inaugurada. Embora existisse a estação de trem Itaquera, não havia ligação entre o terminal do metrô e o trem, o que só se efetivou anos mais tarde, já em 2000, quando a estação ferroviária de Itaquera foi desligada e foram abertas as estações Dom Bosco, José Bonifácio e Guaianases da Companhia Paulista de Trens Metropolitanos (CPTM).

A população habitante no distrito José Bonifácio quadruplicou entre 1980 e 1990, década em que foi construído o conjunto, como indica a Tabela 1.

\begin{tabular}{l|c|c|c|c|c|c|c|c}
\hline & \multicolumn{1}{|c}{ População } \\
\cline { 2 - 9 } & 1950 & 1960 & 1970 & 1980 & 1990 & 2000 & 2010 & $\%$ \\
\hline José Bonifácio & 1.188 & 2.706 & 11.313 & 24.049 & 103.712 & 107.082 & 124.122 & 39,4 \\
\hline
\end{tabular}

Tabela 1. Evolução do censo populacional no distrito de José Bonifácio.

Fonte: IBGE. Censos demográficos, 1950, 1960, 1970, 1980, 1991, 2000, 2010.

A ausência de infraestrutura não era o único problema para as famílias que, vindas de diversas regiões da metrópole, se mudavam para o novo bairro. A apropriação das unidades habitacionais também demonstrava que o sonho da casa própria se efetivava sem todas as garantias inerentes à propriedade. À época da entrega das unidades, os mutuários só recebiam o contrato de compra e venda da Cohab, e não a escritura dos imóveis.

Conforme Silva (2005), na promoção confusa e embaralhada das etapas de regularização dos conjuntos produzidos pelo Estado, não havia, para os mutuários, segurança jurídica oriunda da titularidade da propriedade. A informalidade a que foram submetidas as famílias que se mudaram para as casas e apartamentos da Cohab sem dúvida faz parte das semelhanças em relação ao padrão periférico clássico de ocupação metropolitana, sem a separação, sob esse aspecto, do processo de produção industrial estatal do de construção doméstica. 


\section{Itaquera na "cidade global"}

As transformações que se operaram não significaram uma transição linear, justaposta, entre as fases industrial e urbana, pois estas se imbricaram permanentemente até hoje. Para uma análise global, que nos permita identificar a política do espaço constituída por meio dos projetos urbanísticos e das estratégias mercantis imobiliárias em Itaquera, é preciso verificar que o grande capital privado operou na região no período entre a inauguração do projeto de industrialização habitacional materializado pelos conjuntos e o início desse ciclo contemporâneo de reprodução.

Desde os anos 1960, portanto antes da implementação das habitações da Cohab, as Irmãs Marcelinas respondem pelos serviços de saúde em Itaquera. Nos anos 1970, a instituição criou a primeira unidade hospitalar na zona leste, expandindo desde então o atendimento conveniado com o poder público. $\mathrm{O}$ modelo de convênio e terceirização da saúde pública nessa parte da cidade se gesta imediatamente à criação dos próprios equipamentos públicos. A Organização Social Santa Marcelina monopoliza praticamente a administração das unidades de saúde em Itaquera e tem dominado, mais recentemente, os serviços públicos nesse âmbito nos bairros de Cidade Tiradentes, Guaianases, Vila Formosa, Vila Guilhermina, Itaim Paulista, Ermelino Matarazzo e região metropolitana, especialmente em Itaquaquecetuba 5 .

Outro aspecto fundamental na conformação dessa centralidade regional é a estação terminal do metrô. A partir dela, todos os elementos de centralidade que constituíram Itaquera na transição para o século XXI se desdobraram. A estação, construída pelo Estado e inaugurada no mês de outubro de 1988, passou a ser a mais movimentada da metrópole. Sua imensa área comportou um terminal de ônibus que permitiu o acesso a outras regiões do extremo leste metropolitano. Nos anos 2000, nela se instalou um Poupatempo. Esse conglomerado de diversos órgãos públicos federais, estaduais e municipais é o maior posto entre todos os Poupatempo da região metropolitana, com uma área de quase $9.933 \mathrm{~m}^{2}$ e mais de 10 mil atendimentos diários.

5. Sua expansão na zona leste explica-se principalmente pela realização de reformas de Estado na década de 1990, com a abertura neoliberal que redimensionou o papel de organizações não governamentais, o chamado terceiro setor, nos serviços urbanos essenciais, e que consolidou, assim, a gestão da execução das políticas públicas por meio do modelo de parcerias público-privadas. Atualmente, é um dos maiores empregadores dos moradores do distrito do Parque do Carmo. O Grupo Santa Marcelina, além de deter quase a integralidade dos serviços de saúde na região, é dono de uma faculdade próxima ao centro de Itaquera. Além dela, há mais algumas redes privadas de ensino superior, como a Unicastelo (Universidade Brasil), que se instalou ali em 1970, a Sumaré e a Uninove, o que demonstra que os serviços de saúde e educação, ao que se vê, não são providos diretamente pelo Estado, mas chegam já oferecidos pela concessão ao capital privado nesse processo de urbanização na segunda metade do século passado. 
Anos mais tarde, em 2007, foi construído na mesma área o Shopping Metrô Itaquera (Figura 2), sob a administração do Grupo Ancar Ivanhoe ${ }^{6}$. Em 2017, inaugurou-se a obra de expansão do shopping, que passou a ter uma área bruta de 64 mil m² e 3 mil vagas de estacionamento. O Shopping Metrô Itaquera foi implementado (e mais recentemente expandido) com o discurso da modernização, visto como símbolo do "progresso urbano" que teria se operado na região, elevando em níveis significativos o entrosamento financeirizado e espacializado entre o poder público e o capital privado.

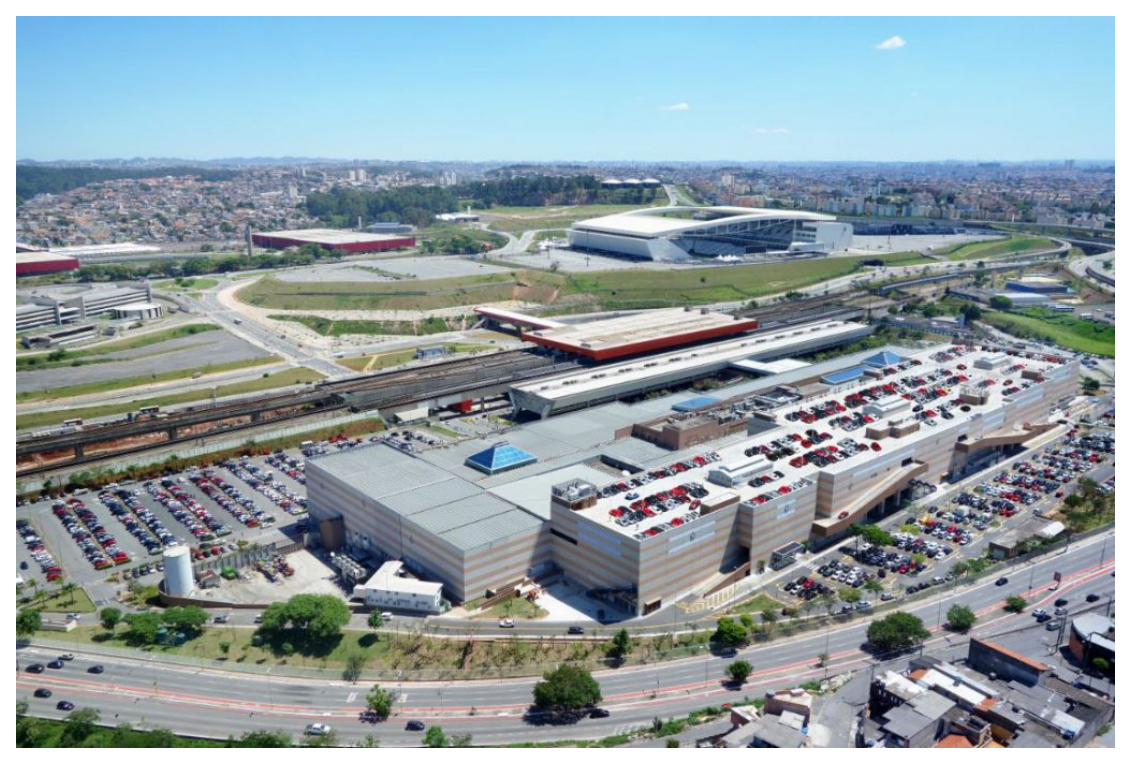

Figura 2. Imagem do Shopping Metrô Itaquera. Ao fundo, respectivamente, o terminal metrô-CPTM Itaquera e a Arena Corinthians.

Fonte: Shopping Itaquera. ${ }^{7}$

6. Essa empresa é resultado de uma associação entre a Ancar, empresa brasileira que iniciou a construção de shoppings centers no Brasil na década de 1970, e o fundo de investimentos canadense Ivanhoe Cambridge. A expansão do grupo foi recentemente noticiada, com a aquisição da rede de shoppings de outro grupo atuante no Brasil. Segundo a notícia, "a Ancar Ivanhoe estaria em negociações para a compra da carteira de shopping centers da Brookfield no Brasil. São cinco empreendimentos - Pátio Paulista, Raposo Shopping, BCP Itaim e BCP Green Valley, em São Paulo, Madureira Shopping, no Rio de Janeiro - avaliados em aproximadamente R 2,5 bilhões. A operação envolveria ainda a aquisição da participação de acionistas minoritários, entre os quais o GIC, fundo soberano de Cingapura, e o PSP, fundo de pensão dos funcionários públicos do Canadá. Por sinal, outro investidor canadense tem um papel de protagonismo nesta negociação. A maior parte dos recursos para a aquisição viria da Ivanhoe Cambridge, braço de real estate do Caisse de Dépôt et Placement du Québec e sócio da família Carvalho na Ancar desde 2006. A Ancar chegaria à marca de 26 shoppings, com vendas somadas da ordem de R\$ 3 bilhões. No mercado, contudo, há quem aposte que a eventual aquisição dos ativos da Brookfield não seria um fim em si mesma, mas o pé de apoio para uma operação muito maior. A Ancar ganharia massa crítica para negociar sua associação com outro grande grupo do setor em condições bem mais favoráveis. Consta que BR Malls e Aliansce já teriam batido à porta”. Ancar Ivanhoe avança sobre os shoppings da Brookfield, 6 fev. 2018. Disponível em: https://relatorioreservado.com.br/assunto/brookfield/. Acesso em: 7 jul. 2019.

7. Disponível em: https://www.shoppingitaquera.com.br/shopping-metro-itaquera. Acesso em: 10 set. 2020. 
Na toada do avanço dos projetos de parcerias público-privadas, em 2009 começa a construção da Arena Corinthians, no terreno público cedido ao clube pela prefeitura na década de 1970. O estádio foi anunciado como a obra que traria o maior progresso a Itaquera, com promessas de desenvolvimento, empregos e entretenimento, mas não apenas: seria o monumento da entrada da metrópole de São Paulo no rol das "cidades globais" no mundo, depois de o Brasil ter sido anunciado como país sede da Copa do Mundo de 2014.

Compreende-se aqui criticamente a noção de cidade global, visto se tratar de uma mitologia contemporânea criada pela cadeia global de reprodução do capital, que metamorfoseia o espaço da cidade apoiando-se em novos ciclos de produção imobiliária e infraestrutural, adequando-se, assim, às exigências da globalização. Segundo Fix (2007), as cidades globais são produto do empresariamento do espaço metropolitano na concorrência mundial pela recepção de investimentos infraestruturais e imobiliários e têm um ingrediente fundamental na criação de novas centralidades.

Vale aqui pontuar que o estádio-arena monumentaliza essa transição da sociedade industrial para a sociedade urbana ilustrada pela imagem da "cidade global”. Nesse caso específico, a periferia tradicional cumpre um papel histórico no “avanço” da metrópole, numa conjunção entre o arcaico e o moderno, entre o local e o global. Os planos urbanísticos no século XXI se apresentam como estratégicos sobretudo porque são dirigidos pelos interesses de mercado. Para se firmarem, exigem a flexibilização da legislação urbana e do zoneamento ${ }^{8}$.

Os novos projetos urbanos objetivam exatamente modificar as funções e as estruturas locais, de modo a consolidar mais fronteiras de expansão do capital, recriadas como "novas centralidades", invenções sobre o espaço que substituem sua vida anterior. As Operações Urbanas aparecem, nesse cenário, como forma de burlar as condições relacionadas à legislação mais rígida relativa ao zoneamento, bem como ao uso e à ocupação do solo, com planos que reforçam a ideia de desenvolvimento de modo mais localizado, em eixos específicos da cidade. Resolver problemas assim configurados e, ao mesmo tempo, superar a permanente justificativa de falta de verba para a aplicação de investimentos por parte do Estado, com o protagonismo do mercado na execução de projetos e obras, são os discursos que embasam esse processo de reestruturação imobiliária.

\footnotetext{
8. No caso de Itaquera, diferentemente do que houve no fim do século XX no quadrante sudoeste, que compreende a avenida das Nações Unidas, a Marginal Pinheiros e a Nova Faria Lima (FIX, 2007), não houve propriamente substituição das áreas industriais pelos setores de serviço e comércio, numa intensa transformação do uso e ocupação do solo, mas nitidamente se tentou abrir uma fronteira para a criação de uma nova centralidade apropriável pelo mercado imobiliário por meio da grande área ao redor da pedreira, que se manteve vazia de usos por muitas décadas.
} 
É nesse espírito que a Operação Urbana Rio Verde-Jacu é aprovada em julho de 2004, em decorrência da Lei Municipal n. 13.872. Seu objetivo, entre outros, de acordo com a própria redação da lei, consiste em criar intervenções na zona leste, especialmente em Itaquera, onde deveria ser consolidado um "centro polarizador" de investimentos para reestruturação imobiliária. Propuseram-se, para tanto, um "Polo Institucional junto à Estação Itaquera do Metrô e [...] a reestruturação do Polo Econômico Leste”, como apresenta a Figura 3. Essa foi a primeira operação urbana lançada numa região periférica em São Paulo, o que denota a importância repaginada de Itaquera nos novos planos contemporâneos de produção da metrópole.

Polo Institucional Itaquera - Plano Geral (proposta)

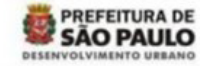

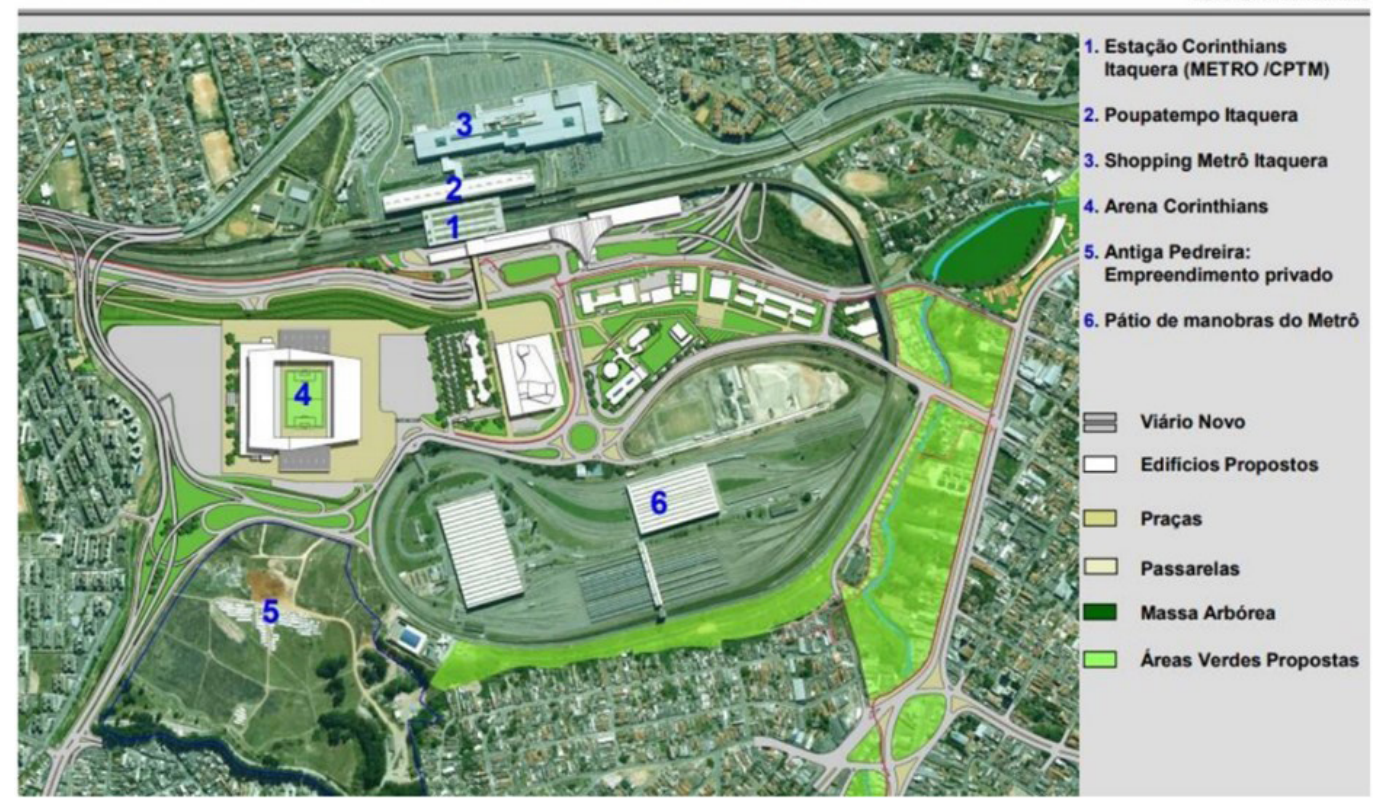

Figura 3. Projeto de Polo Institucional e Tecnológico de Itaquera

Fonte: Prefeitura Municipal de São Paulo, 2012.

A Odebrecht, maior conglomerado empresarial do Brasil à época, foi responsável pela coordenação do consórcio de empresas que construiu a Arena Corinthians e o complexo viário previsto no projeto do Polo Institucional. Segundo a Matriz de Responsabilidades da Copa do Mundo 2014, o poder público seria obrigado a aportar as obras de infraestrutura para acesso e mobilidade referentes aos locais onde o evento seria realizado, o que foi instrumentalizado prontamente pelo lançamento do projeto do Polo. O megaevento, nesse sentido, criou as soluções necessárias e institucionais para a reprodução do espaço e a valorização imobiliária desse 
novo lugar ao redor do estádio, isentando o capital privado de responsabilidades fiscais e de custeio das obras 9 .

Foi relevante, nesse contexto de reestruturação imobiliária, a valorização do metro quadrado nos arredores do Polo e da área onde seria estabelecido o Parque Linear Rio Verde. Previsto no Plano Diretor de 2002, com base no Programa de Recuperação Ambiental de Cursos d’Água e Fundos de Vales, o parque foi especialmente controverso na época da construção da Arena e do Polo porque seu projeto previa a desapropriação da Favela da Paz, comunidade que há mais de trinta anos habita uma área a 800 metros do estádio e sofre permanentes ameaças de remoção pelo poder público. A concepção de um parque que contivesse espaços de lazer e promovesse a preservação ambiental, combinado com o estádio e as obras viárias, corroborou o processo intenso de valorização e o lançamento de empreendimentos imobiliários na região $0^{10}$, conferido nos dados demonstrados na Tabela 2 e no Gráfico 1.

\begin{tabular}{c|c|c|c|c}
\hline Período (mês de maio) & Centro & Itaquera & Pinheiros & Tatuapé \\
\hline 2009 & 15,91 & 8,33 & 18,32 & 12,55 \\
\hline 2010 & 17,24 & 8,70 & 24,00 & 13,49 \\
\hline 2011 & 20,06 & 12,15 & 24,75 & 15,45 \\
\hline 2012 & 25,53 & 14,87 & 33,33 & 17,58 \\
\hline 2013 & 23,88 & 13,12 & 35,09 & 17,75 \\
\hline 2014 & 25,94 & 16,25 & 36,35 & 20,91 \\
\hline 2015 & 26,30 & 16,46 & 32,33 & 21,01 \\
\hline 2016 & 23,20 & 15,64 & 34,44 & 19,00 \\
\hline 2017 & 23,49 & 16,44 & 33,00 & 19,91 \\
\hline
\end{tabular}

Tabela 2. Valorização do aluguel em Itaquera por metro quadrado, de 2009 a 2017.

Fonte: Secovi-SP, $2017^{11}$ (organizada pela autora).

9. Além das verbas para a construção do complexo viário para automóveis, o montante usado para a implantação da Arena Corinthians foi levantado mediante empréstimos do Banco Nacional de Desenvolvimento Social (BNDES) e pela Caixa Econômica Federal (CEF), além dos incentivos de desenvolvimento certificados também pelo poder público. As instituições financeiras e a prefeitura emprestaram ao Sport Club Corinthians Paulista e ao Grupo Odebrecht cerca de um bilhão de reais.

10. Segundo o índice FipeZap, no ano de 2012, quando esse processo estava em curso, o aumento dos preços na região foi de 50\%. Em 2014, Itaquera foi a subprefeitura com maior número de lançamentos imobiliários da cidade, com oferta de mais de 2.500 unidades naquele ano, com média de valor aproximada de $\mathrm{R} \$ 4.500,00$ a unidade do metro quadrado.

11. Sindicato das Empresas de Compra, Venda, Imóveis (Secovi-SP). Pesquisa Mensal de Valores de Locação Residencial Cidade de São Paulo: abr. 2018. Disponível em: http://www.secovi.com.br/downloads/ pesquisas-e-indices/pml/2018/arquivos/201804-pml.pdf. Acesso em: 10 ago. 2020. 
Imóvel residencial de 1 dormitório, em bom estado de conservação Variação percentual acumulada - Itaquera

\begin{tabular}{|l|r|}
\hline \multicolumn{2}{|c|}{$\begin{array}{c}\text { Variação acumulada (\%) } \\
\text { Maio de 2012 a Abril de 2018 }\end{array}$} \\
\hline IGP-M (FGV) & $39,8 \%$ \\
\hline Município São Paulo & $13,5 \%$ \\
\hline 1 Dormitório & $34,1 \%$ \\
\hline
\end{tabular}

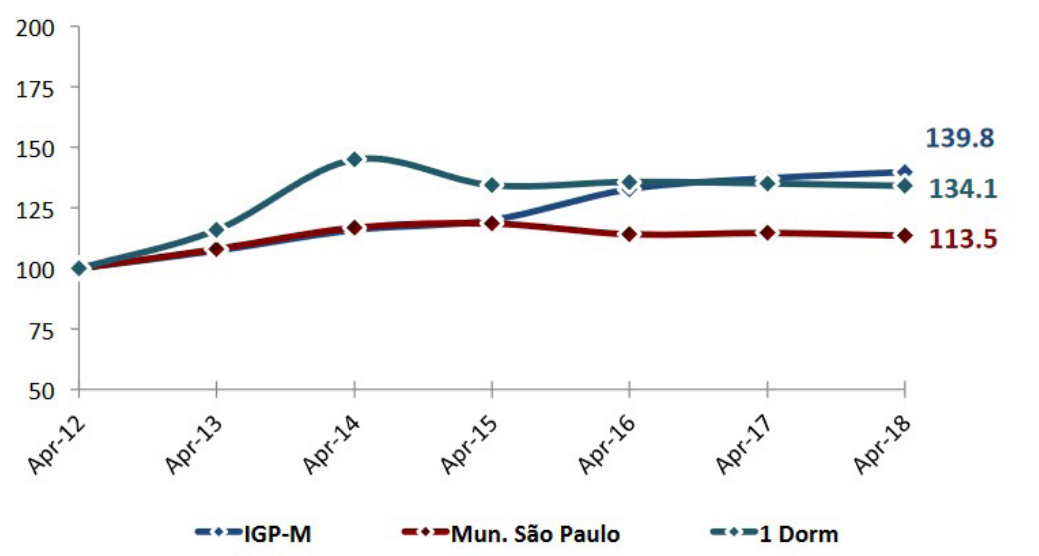

Gráfico 1. Variação percentual acumulada de maio de 2012 a abril de 2018 do metro quadrado de imóveis residenciais de um dormitório em Itaquera

Fonte: Secovi-SP, 2017.

A valorização imobiliária em Itaquera nesse período foi acompanhada por um processo anterior, iniciado nos anos 2000, com incidência em diversas periferias metropolitanas, de expansão de lançamentos imobiliários residenciais privados para o chamado "segmento econômico"'2.

A ampliação do mercado imobiliário para estratos médios da classe trabalhadora e para a classe média baixa, "consumidores potenciais", deveu-se ao incremento da renda desses setores, à ampliação legal de garantias em operações de

12. Segundo Castro e Shimbo (2010, p. 54): "A partir dos anos 2000, a consolidação do processo de estabilização significou, ao mesmo tempo, crescimento econômico, ganhos na renda dos estratos médios e baixos da população e maior concentração da produção imobiliária em grandes empresas. Nesse processo, o ano de 2006 representou um momento de virada, quando se iniciou a financeirização de grandes empresas construtoras e incorporadoras, concomitantemente às medidas regulatórias que favoreceram e ampliaram enormemente o montante de recursos públicos e semipúblicos destinados ao financiamento habitacional, voltado diretamente ao consumidor. Iniciava-se, a partir de então, a produção financeirizada da habitação, fortemente apoiada pelo Estado e fomentada pelo capital financeiro". CASTRO, C. M. P. de; SHIMBO, L. Z. Das cooperativas autofinanciadas às construtoras e incorporadoras de capital aberto: a ampliação do mercado habitacional. Revista brasileira de estudos urbanos e regionais. Salvador: Anpur, n. 2, p. 53-73, 2010. 
financiamento imobiliário e à expansão de crédito com a flexibilização de critérios, que revelam uma modificação contundente no papel do capital financeiro como agente da produção do espaço urbano.

A grande expectativa no poder de consumo da chamada "classe C", alimentado pela imprensa e pelo governo federal na primeira década dos anos 2000, simbolizava a aposta na via do endividamento para a "incorporação" desses segmentos econômicos ao mercado habitacional como público comprador dos empreendimentos dos projetos de padrão arquitetônico homogêneo, construídos em larga escala em regiões de terrenos mais baratos na metrópole, como Cotia, Guarulhos, $\mathrm{ABC}$ e diversos bairros da zona leste. Pouco tempo depois, ao longo da crise financeira mundial em 2008, o Estado reforçou seu aporte ao empresariado ligado aos negócios imobiliários. Refundou-se ideologicamente o clamor por uma atuação governamental para a conquista da "casa própria”, similarmente ao que se passou entre as décadas de 1960 e 1980, e uma verdadeira enxurrada de subsídios e verbas de financiamento para a produção e o consumo de habitação foi transferida ao setor imobiliário (RUFINO, 2017, p. 233).

O Programa Minha Casa Minha Vida (PMCMV) foi lançado pelo governo federal em 2009 com o objetivo de promover a produção e o consumo de habitação para famílias com renda de um a dez salários mínimos. Tornando-se mais tarde o maior programa habitacional da história do país, ultrapassou em investimento o projeto do BNH e foi, como citado, desenhado em aliança com o grande empresariado da construção e da incorporação imobiliária. O PMCMV garantiu o deslocamento, sem riscos, desse ramo para a provisão de moradias dos segmentos econômicos por meio do financiamento da produção e da organização da demanda para o consumo.

O PMCMV reforçou a estratégia dos anos 2000 dessas grandes empresas, que abriram subsidiárias de segunda linha para o dito "segmento econômico" ou compraram empresas menores que já tinham esse perfil de mercado, assentadas na garantia da ampliação do crédito para aquisição de imóveis por meio do Programa. Abaixo, para fins ilustrativos, apresenta-se o panfleto de empreendimento residencial desse tipo lançado pela Living, construtora ligada ao grupo Cyrella (Figura 4).

As mudanças no mundo do trabalho e do consumo decerto devem ser levadas em consideração na reprodução do espaço em transformação constante, que, ao menos aparentemente, dá lugar ao consumidor emergente em substituição ao trabalhador pobre, que passa a procurar alternativas em regiões da metrópole nas quais a valorização diferencial do solo urbano não tenha ocorrido com a mesma intensidade. A capacidade de ser comprador, de ser proprietário formal, torna-se, então, condição para habitar a área nos arredores das comunidades faveladas, como a mencionada Favela da Paz. 

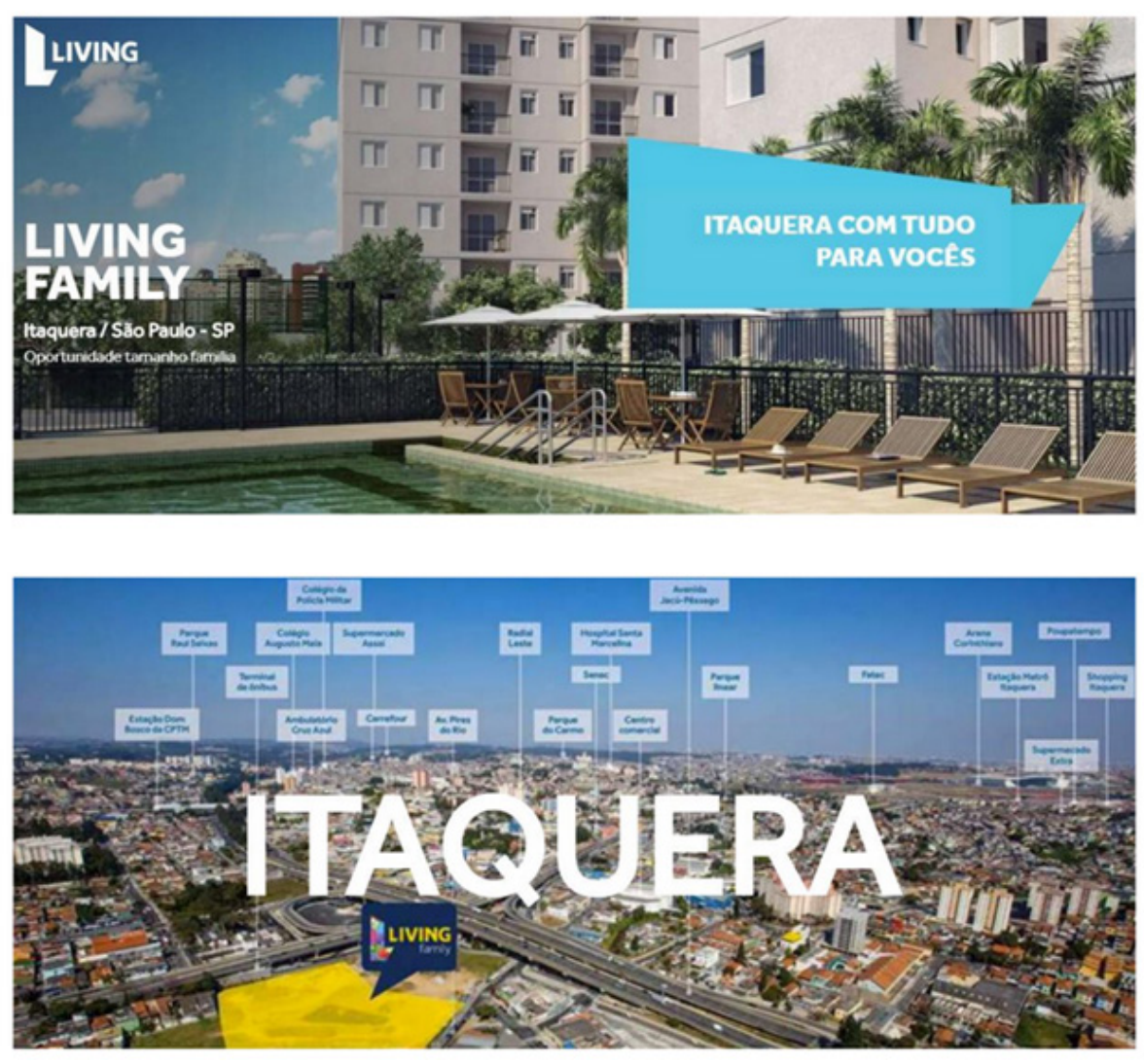

Figura 4. Exemplo de lançamento imobiliário recente em Itaquera Fonte: Living Construtora'3, 2020.

A reestruturação imobiliária implica uma dinâmica de dominação espacial que hierarquiza novos hábitos de consumo, circulação e habitação. Essa transformação de Itaquera certamente teve condições diferenciadas em comparação a outras periferias mais antigas, em razão da disponibilidade de terras públicas para a construção da infraestrutura de transporte e para a política habitacional. Isso será considerado em seguida para a apresentação do exemplo da Cohab José Bonifácio.

\section{O Condomínio Residencial José Bonifácio}

Na década de 1980, os conjuntos habitacionais e o metrô representaram um avanço inédito, em intensidade, do Estado sobre a periferia "não dominada” (DAMIANI, 1993, p. 89-9o), que, até aquele momento, ainda misturava o subúrbio com elementos rurais e os loteamentos clandestinos de casas produzidas domesticamente.

13. Disponível em: http://www.meuliving.com.br. Acesso em: 10 ago. 2020. 
O questionamento que resta fazer é como o ambiente fixado pela construção da Cohab José Bonifácio, da clássica cidade-dormitório, cujo porte, com 120 mil habitantes, é comparável ao de cidades médias, interage com a chegada desse movimento mais recente de mercantilização do espaço. Diferentemente de Itaquera, José Bonifácio é um distrito composto basicamente das casas e edifícios construídos à época do projeto do BNH, ao norte, e por áreas ainda rurais, ao sul. Não houve ali, portanto, a possibilidade, na mesma intensidade e condições, de apropriação dos seus vazios urbanos ou da reestruturação imobiliária nos termos em que o espaço foi ajustado no distrito vizinho.

As comparações entre os dois distritos evidenciam as diferenças do que foi concebido na aliança público-privada em avanço na dominação do espaço: enquanto Itaquera se destaca como distrito com o maior índice de empregos formais, José Bonifácio ocupa a última posição, mesmo sendo o distrito com maior taxa de crescimento populacional da subprefeitura (SMDU, 2012). Além disso, os dados demonstram que José Bonifácio é o distrito da região com menos habitantes com formação no ensino superior completo e também aquele com o menor número (absoluto e relativo) de domicílios com renda de dez a vinte salários mínimos e com mais de vinte salários mínimos. A ampla maioria das famílias se situa na faixa de dois a cinco salários mínimos.

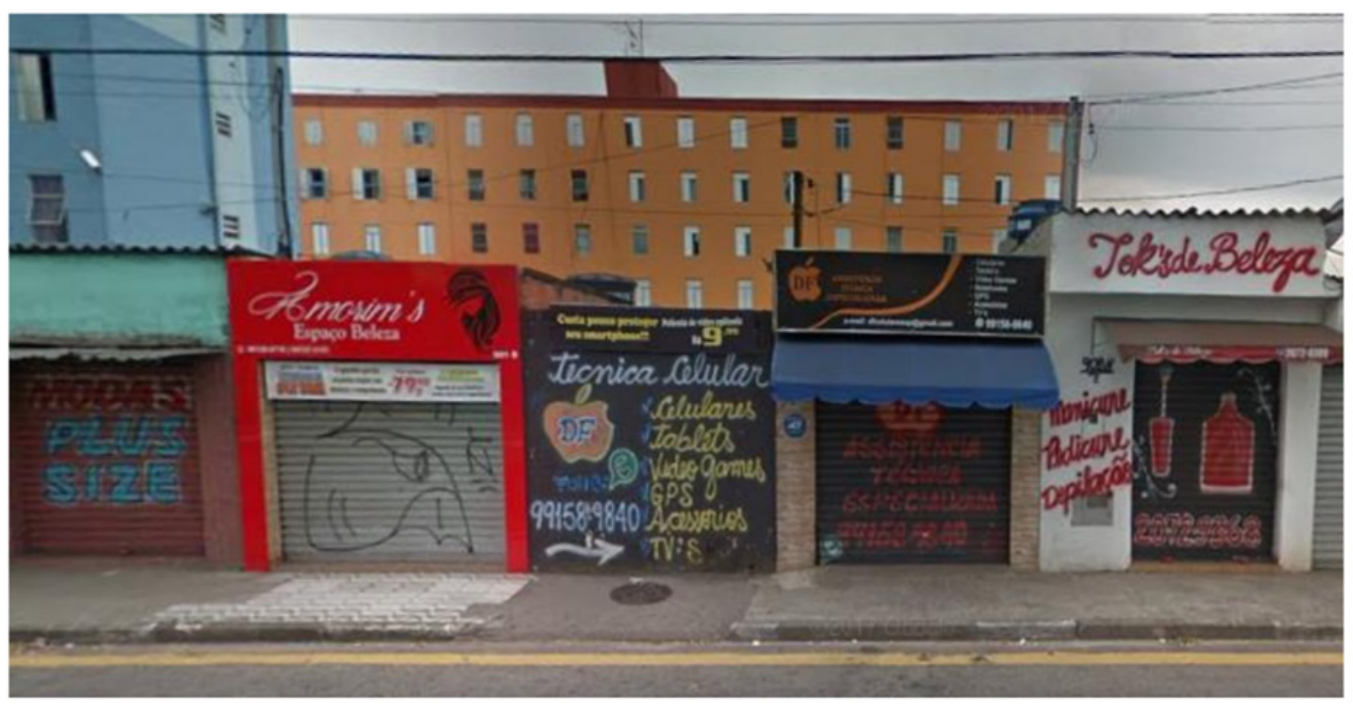

Figura 5. Imagem do comércio na avenida Nagib Farah Maluf Fonte: GoogleStreet, 2020.

José Bonifácio, em termos socioeconômicos e infraestruturais, seria, nesse sentido, a "periferia” da região de Itaquera. Uma “vocação”, em grande medida, associada às condições espaciais que historicamente foram planejadas e produzidas 
pelo Estado. O fato de seu espaço ser morfologicamente menos "flexível" do que o do centro da subprefeitura e suas imediações não impediu, no entanto, que o processo de consolidação e apropriação do espaço se desse com nuances particulares. Passaram-se quase quarenta anos da inauguração da Cohab 2 e as apropriações sedimentadas ali são diversas. Com mais destaque, ao menos ao que parece, veem-se áreas públicas (originalmente destinadas a equipamentos e serviços que nunca foram implementados) privatizadas pelos edifícios e garagens construídos depois da entrega original do Conjunto. Elas foram transformadas, em larga medida, em pontos comerciais irregulares, que respondem pelas necessidades mais cotidianas dos moradores, como serviços de padaria, lojas de vestuário, cabeleireiros, bares, bombonières e mercadinhos (Figura 5).

Basicamente, em todas as grandes vias que permeiam o Conjunto há comércio informal nas garagens dos condomínios. Essa apropriação popular das benfeitorias feitas pelos moradores consolidou um mercado imobiliário informal na área, dirigido à locação de sedes para pequenos empreendimentos, os quais viabilizam fonte de renda e trabalho e, com a prestação de serviços e o comércio, atendem a necessidades mais emergenciais. Segundo os moradores entrevistados para o estudo, o aluguel da garagem, que tem em média $12 \mathrm{~m}^{2}$, varia entre $\mathrm{R} \$ 500$ e $\mathrm{R} \$ 800$, dependendo da localização em avenidas e ruas mais movimentadas. Nas principais ruas e avenidas do Conjunto - rua Virgínia Ferni, rua Jardim Tamôio, rua Sílvio Barbini, avenida João Batista Conti, avenida Nagib Farah Maluf-, os comércios de garagem estão presentes.

Circulações, trocas e serviços se devem sobretudo a esse comércio desenvolvido informalmente pelos moradores ao longo das décadas. Mas, se em termos históricos o mercado imobiliário de locação de garagens e a própria utilização das garagens para ativação dos comércios e serviços foram fruto de apropriações populares, feitas pelos habitantes da Cohab - que encontraram nos vazios e nos espaços adaptados a possibilidade de se tornarem trabalhadores autônomos e pequenos empreendedores -, hoje já dividem o espaço com uma pequena burguesia comercial, formalizada e mais estruturada do que os pequenos negócios das garagens. Cresce o número de pizzarias, farmácias e franquias de grandes redes populares de cosméticos.

Também houve a expansão de um capital comercial robusto, que prevaleceu e foi significativamente responsável pelo processo de fragmentação e negação do urbano na área da Cohab 2. Os hipermercados, ambientes comerciais de grandes empresas privadas do varejo, são espaços de predileção do capital para expandir-se às periferias. São elementos sentidos da reestruturação imobiliária do Conjun- 
to, visto que ocupam áreas extensas, que contrastam com os lotes estabelecidos para os prédios residenciais e produzem longas passagens sem esquinas ou diversidade de usos.

As marcas Lopes, ITA, D’Avó, Negreiros e Extra - todas de empresas especializadas no grande varejo nas periferias - são as principais estabelecidas ali. A Cohab e seu ritmo inédito de adensamento na década de 1980, com dezenas e dezenas de milhares de moradores, tornou-se um espaço apto à reprodução do capital comercial no ramo de alimentos e produtos de uso doméstico que, ao reproduzir-se, modificou o ambiente construído, transformando as relações sociais.

Segundo Rolnik e Frúgoli (2001, p. 49):

[...] a partir dos anos 1990, grandes shoppings e hipermercados têm também se instalado, de forma dispersa, nas periferias da cidade, junto a grandes eixos de acessibilidade, muitas vezes em área de urbanização incompleta. Essa territorialização, que justapõe grandes shoppings centers, pequenos estabelecimentos de comércio e serviços em assentamentos residenciais populares, produz uma nova espacialidade da desigualdade, constituindo uma estrutura em que convivem a fragmentação e a dualização [...] mais do que reforçar uma dualização entre incluídos e excluídos, centro/periferia, a nova ordem espacial na cidade segue um modelo muito mais fractal, no qual a tensão entre o avançado e o arcaico, o inserido e o excluído, o legal e o ilegal se reproduz infinitamente no espaço.

Mas não são apenas os milhares de apartamentos no entorno da loja de materiais que formam a demanda da região por reformas físicas nos imóveis. Nos últimos anos, a construção de muros, a instalação de grades e portões elétricos, além de outros equipamentos de segurança patrimonial, também formam a paisagem dos condomínios fechados. Aparentemente, essas benfeitorias se generalizam pelas ruas e avenidas observadas na pesquisa de campo. Em essência, dão-se no marco de um processo de transformação no regime de propriedade do conjunto em condomínio.

Novos empreendimentos, talvez mais atados à forma condomínio tal como é concebida nessa fase de reestruturação imobiliária na metrópole, são igualmente identificados no bairro. Os projetos do PMCMV, que selaram ali a parceria do governo federal com a Cohab-SP, estão presentes. São projetos em andamento ou já construídos, voltados à faixa 1 e 2 do Programa e também ligados ao PMCMV-Entidades (PMCMV-E).

Os novos produtos imobiliários do Programa, que não distinguem mais "as formas pública e privada de produção”, consolidando o modelo que Shimbo (2012) denomina "habitação social de mercado", também são marcados pela qualidade 
construtiva peculiar, um elemento de diferenciação em relação às edificações da Cohab nos anos 1970-1980. Em razão de o Estado ter sido responsável pela condução das obras (não obstante empreiteiras privadas tenham sido contratadas para as construções) na era do $\mathrm{BNH}$, houve alguma responsabilidade do poder público com os reparos, as reformas necessárias, a implantação de equipamentos e serviços públicos ${ }^{14}$.

A produção habitacional mais recente na Cohab 2 não se resume apenas aos novos condomínios do PMCMV. Embora muito tímida, há alguma inserção de empreendimentos residenciais de incorporadoras privadas também nas fronteiras do conjunto, como os da Econ Construtora e Incorporadora Ltda., localizados na Estrada Itaquera-Guaianazes, fronteira do conjunto ao seu norte. Com vistas a assegurar a ampliação dos ganhos na produção de habitação para esse segmento, grandes empresas de incorporação e de construção articularam três estratégias fundamentais: padronização da construção, geração de economia de escala e procura de terrenos baratos. De maneira implícita, tais estratégias disseminam a forma condomínio, que permite a consolidação de uma produção intensiva nas áreas periféricas por meio da organização de muitos blocos de edifício numa urbanização fragmentada (RUFINO; SHIMBO, 2016, p. 3).

Chama atenção que o principal atrativo dos empreendimentos, segundo as divulgações publicitárias, está no fato de serem os primeiros "condomínios clubes da região”, com localização próxima ao shopping, à estação de metrô e à estação José Bonifácio da CPTM. No discurso, é vendida uma vida de praticidades e de atendimento a necessidades familiares no ambiente privado, como lazer para adultos e crianças, exercícios físicos, contato com o "verde”, entre outras "facilidades”.

Os empreendimentos novos lançados por incorporadoras privadas são minoritários porque não há terrenos vazios para a produção no perímetro do Conjunto. Trata-se, em parte, da escassez de áreas para construção, em virtude da ocupação dos edifícios produzidos no ciclo anterior pela Cohab. Em outra parte, a área é propriedade da Cohab, o que torna mais provável que as novas construções sejam feitas com o apoio do PMCMV, na parceria da CEF com a Cohab, que disponibiliza os terrenos.

\footnotetext{
14. Isso ocorreu em decorrência tanto do papel formal protagonista na provisão habitacional como da pressão política sobre o Estado para melhorias por meio da organização popular ou das relações clientelistas com os mutuários. O mesmo não parece ocorrer nas obras do PMCMV. Além da qualidade da construção, os projetos têm áreas privativas e comuns reduzidas nos condomínios; no caso em questão, foram alocados às margens do próprio Conjunto, nos vazios onde a Cohab não concretizou nenhum projeto, nas proximidades das áreas de vegetação, nos limites do Conjunto. Trata-se de um reforço segregacionista dos empreendimentos do programa habitacional nesse novo ciclo imobiliário no Brasil.
} 
A ação da Cohab no que se refere à organização dos vazios e incompletudes parciais parece ser ineficiente, ainda mais quando vista em comparação com a real reabilitação em curso, que ocorre com a reestruturação imobiliária resultante do crescimento da forma condomínio. A clássica noção de "bairro-dormitório" não deixa de estar presente nesse novo modo de apropriação do espaço do conjunto: antes produção e propriedade do Estado, passa a ser reprodução e apropriação de proprietários privados. Mas essa forma apropriada não deixa de produzir a segregação, a fragmentação e a negação do urbano que já existiam na década de 1980, quando o Conjunto ainda apresentava essencialmente sua concepção original.

Em realidade, a forma condomínio reitera a antiga concepção, complexificando seu sentido em face da maneira como atualmente se assenta a propriedade imobiliária. O condomínio se estabelece, portanto, particularmente como "fronteira da fronteira", marcado pela transição para a forma da propriedade condominial sem, com isso, se efetivar uma substituição plena da condição de conjunto habitacional, que permanece em grande medida pela continuidade da propriedade da Cohab-SP e pelo uso e ocupação do solo restrito à habitação; suas outras funções e estruturas (como as garagens, os comércios e até mesmo as imobiliárias) são desdobramentos dessa permanência.

\section{Considerações finais}

Esta breve análise sobre alguns dos elementos que compõem o processo de consolidação da região de Itaquera, e particularmente do Conjunto José Bonifácio, aponta para o fato de que os principais modelos que permearam o pensamento urbano brasileiro não se aplicam com exatidão ao passado histórico dessa área da metrópole de São Paulo e, com mais contundência, não se compatibilizam com os processos mais recentes de reestruturação imobiliária pelos quais vem passando.

Para que a compreensão científica desses processos encontre a realidade e suas repercussões, foi preciso retomar com mais especificidade a trajetória da formação socioespacial do caso em estudo. No tocante a Itaquera, a expansão de investimentos imobiliários por meio do planejamento urbano e de grandes projetos se combinou com a proposta de apelo nacional e internacional, a Arena Corinthians, que alavancou outros planos estacionários anteriores de obras de infraestrutura viária na região, como o complexo de ligações entre a avenida Radial Leste e a avenida Jacu-Pêssego, continuação da rodovia Ayrton Senna, que liga São Paulo ao Rio de Janeiro e à rodovia Imigrantes, por meio do trecho leste do rodoanel. Uma nova alavanca, diferente, mas que guarda alguma semelhança com o ciclo de produção no período do regime ditatorial no que diz respeito ao apelo ideológico do "progresso da periferia". 
São diferentes o ritmo e a qualidade que envolvem a consolidação da Cohab, porque é especialmente possível que sua forma concebida de bairro-dormitório tenha gerado, como saída para uma nova fase de expansão de capital, outras modalidades de apropriação. Essa modalidade passa pela adaptação da produção do ciclo anterior ao processo de condominialização e "imobiliarização". Uma transformação na forma de propriedade - do Estado para os proprietários individuais - que determina a reprodução de novas relações sociais.

A saída de cena do Estado como provisor habitacional e protagonista das políticas urbanas revela um projeto latente de fragmentação, extensivo e intensivo:

[...] há um "projeto consensual implícito de cidade”, a cidade produzida pelo mercado, não se tratando de uma exceção. E como são os promotores privados aqueles que constroem as novas espacialidades, a mobilização em torno das melhorias dos edifícios e casas torna-se dispersa, frágil, atomizada e individualizada. Trata-se de um processo de descentralização do agente produtor dos espaços habitacionais [...] (VOLOCHKO, 2011, p. 202).

Essa fragmentação é, no caso estudado, consequência histórica do projeto de urbanização de Itaquera e, em específico, do Conjunto Habitacional José Bonifácio. Por um lado, as unidades do Conjunto Habitacional original foram entregues aos mutuários essencialmente como valor de uso, visto que o contrato com a Cohab não previa, ao menos não em um primeiro momento, a titularidade da propriedade das casas e apartamentos.

O processo de quitação dos imóveis, fosse em negociação direta dos indivíduos e famílias com a Cohab, fosse por meio dos programas lançados pela Cohab principalmente nos anos 2000 para a transferência de títulos em forma de mutirões, permitiu aos moradores a conversão da condição de mutuários para a de proprietários condôminos. Essa condição jurídica, que supera a precariedade da posse, capacita o valor de troca dos imóveis no mercado formal (desconsiderando aí todos os chamados "contratos de gaveta" que alimentam um mercado informal de imóveis muito comum nas áreas periféricas metropolitanas) e "libera” o conjunto de imóveis da gestão direta do Estado.

Com isso, a forma condomínio,

[...] como instituição jurídica específica que regulamenta a multiplicação de propriedades e normatiza a convivência de vizinhos, representa na atualidade um importante meio de privatização dos espaços periféricos. A ampliação de sua escala, decorrente de transformações estruturantes na produção imobiliária, e disseminação para os mais pobres potencializa esse processo ao mesmo tempo em que expõe suas limitações (RUFINO; SHIMBO, 2016). 
Voltando às diferenças entre os dois ciclos de investimento em Itaquera, pode-se aferir que a primeira distinção é a do papel do Estado na produção do espaço. Se o regime ditatorial desenhou, organizou e executou o projeto habitacional, criando, para tanto, o BNH e as Cohabs e contratando construtoras como agentes executores dos projetos, o ciclo contemporâneo notabiliza uma ampliação do papel do mercado, considerando que é de sua responsabilidade não apenas a construção efetiva das habitações, como também o desenho dos projetos, como fica evidente no PMCMV.

O Estado age como organizador dos interesses do mercado de imóveis, mas não figura mais com protagonismo na sua consecução. Os grandes projetos urbanos e megaeventos, como a Copa do Mundo, identificam essa característica. A novidade do segundo ciclo em relação ao primeiro não é exatamente o surgimento do Estado como patrocinador dos interesses do capital. Esse caráter do Estado é permanente e existiu com preponderância quando se criou o BNH como programa anticíclico apto a alavancar a indústria da construção em um momento de grave crise econômica e social.

Ocorre que há uma complexificação de interesses, qual seja, a primazia dos agentes vinculados ao capital financeiro no processo de formação do valor imobiliário, não mais ditado simplesmente pelo capital produtivo-industrial da construção, como antes ${ }^{15}$. As novas leituras da metrópole, resultantes dos processos de reestruturação, fragmentação, hierarquização e homogeneização, podem quebrar o dualismo que tradicionalmente marcou a grande literatura sobre o urbano latino-americano.

Pondera-se aqui se o caso de Itaquera não quebra, ainda, um possível dualismo nessas novas análises sobre a produção do espaço, relativo à diferenciação entre a operação dos agentes vinculados ao capital financeiro no centro e na periferia da metrópole. Se, no centro, a força do imobiliário é demonstrada por meio dos grandes projetos urbanos (FIX, 2007) e, nas periferias, é marcada pela expansão na produção de empreendimentos habitacionais subsidiados pelos programas estatais (VOLOCHKO, 2011), Itaquera condensa as duas hipóteses: Operação Urbana, Parque Linear e estádio-arena com fortes incentivos fiscais, por um lado, e condo-

\footnotetext{
15. De acordo com Rufino (2017, p. 215): “Assim, pode-se afirmar que o processo da centralização do capital evidenciado na atualidade é produto da emergência do domínio do capital financeiro que, sustentado na grande mobilidade alcançada pela liberalização e articulação dos sistemas monetários e financeiros em escala nacional e internacional e na grande sofisticação de estruturas e mecanismos de organização desse capital (fundos de pensão, fundos de investimento, sociedade de ações etc.), tende a se direcionar para os setores que permitam melhores condições de rentabilizar esse capital. Dentro dessa racionalidade, a produção imobiliária também passará por importantes mudanças visando atender as expectativas do capital financeiro".
} 
mínios para o segmento econômico combinados com a realização de projetos do PMCMV, por outro. Nesse sentido, afirma Smith (2007, p. 17): "A potência da imagem de fronteira depende da sutileza presente nesta combinação do econômico com o espacial”. No passado, a expansão do capital foi possibilitada pela ampliação geográfica absoluta no processo de urbanização de Itaquera; hoje, contudo, é possível identificar elementos de diferenciação interna ao seu espaço que cumprem esse objetivo, produzindo um novo tipo de segregação. Como Smith comenta, as fronteiras decorrentes da diferenciação do espaço urbano são econômicas, mas também de outras naturezas, produzindo um emaranhado de transformações na totalidade da vida cotidiana.

\section{Referências}

BOLAFFI, G. Habitação e urbanismo: o problema e o falso problema. In: SIMPÓSIO DE HABITAÇÃO DA XXVII REUNIÃO ANUAL DA SOCIEDADE BRASILEIRA PARA O PROGRESSO DA CIÊNCIA, 1975. São Paulo. Anais [...]. São Paulo: SBPC, 1975.

CAMARGO et al. (orgs.). São Paulo 1975: crescimento e pobreza. São Paulo: Loyola, 1975.

CUNHA, R. C. da. Morador de Itaquera vê a Copa do Mundo como promessa de melhorias no bairro. 12 jun. 2013. Disponível em: https://mural.blogfolha.uol.com.br/2013/o6/12/morador-de-itaquera-ve-a-copa-do-mundo-como-promessa-de-melhorias-no-bairro/. Acesso em: 10 set. 2020.

DAMIANI, A. L. A Cidade (des)ordenada: concepção e cotidiano do Conjunto Habitacional Itaquera I. 1993. (Tese de Doutorado) - Faculdade de Filosofia, Letras e Ciências Humanas, Universidade de São Paulo, São Paulo, 1993.

FIX, M. São Paulo, cidade global: fundamentos financeiros de uma miragem. São Paulo: Boitempo, 2007.

IBGE. Censos demográficos, 1950, 1960, 1970, 1980, 1991, 2000, 2010. Secretaria Municipal de Desenvolvimento Urbano (SMDU); Departamento de Estatística e Produção de Informação (Dipro). Disponível em: http://smul.prefeitura.sp.gov.br/historico_demografico/ tabelas/pop_dist.php. Acesso em 7 jun. 2018.

KOWARICK, L. Escritos urbanos. São Paulo: Editora 34, 2000.

LEFEBVRE, H. A revolução urbana. Belo Horizonte: Editora UFMG, 1999.

Direito à cidade. São Paulo: Centauro 2001.

MARICATO, E. A produção capitalista da casa (e da cidade) no Brasil industrial. São Paulo: Alfa-Ômega, 1979.

Indústria da construção e política habitacional. 1984. (Tese de Doutorado) - Faculdade de Arquitetura e Urbanismo, Universidade de São Paulo, São Paulo, 1984. 
MAUTNER, Y. A periferia como fronteira de expansão do capital. In: DEÁK, C.; SCHIFFER, S. R. (orgs.). O processo de urbanização no Brasil. 2. ed. São Paulo: Edusp, 2010.

PEREIRA, P. C. X. Reestruturação imobiliária em São Paulo: especificidades e tendências. In: X Encontro de Geógrafos da América Latina. Anais [...]. São Paulo: Universidade de São Paulo, 2005.

PREFEITURA MUNICIPAL DE SÃO PAULO. Polo Institucional Itaquera: diretrizes de projeto urbanístico. São Paulo: Secretaria Municipal de Desenvolvimento Urbano (SMDU); Assessoria Técnica de Operação Urbana (Atou), 2012.

RAMALHOSO, W. Destino Itaquera: o metrô rumo aos conjuntos habitacionais da Cohab-SP. 2013. Dissertação de Mestrado - Instituto de Arquitetura e Urbanismo, Universidade de São Paulo, São Carlos, 2013.

ROLNIK, R.; FRÚGOLI JR., H. Reestruturação urbana da metrópole paulistana: a Zona Leste como território de rupturas e permanências. Cadernos Metrópole. São Paulo, n. 6, p. 55-83. 2001.

RUFINO, M. B. C. Financeirização do imobiliário e transformações na produção do espaço. In: FERREIRA, A.; RUA, J.; MATTOS, R. C. de. (orgs.). o espaço e a metropolização: cotidiano e ação. Rio de Janeiro: Consequência, 2017.

RUFINO, M. B. C.; SHIMBO, L. Z. Financeirização e condominialização: um olhar sobre as transformações na produção e na propriedade da habitação no Brasil. In: CONGRESO INTERNACIONAL CONTESTED_CITIES. Madrid, Grupo de Estudios Urbanos y Teoría Social. 2016.

SHIMBO, L. Z. Habitação social de mercado: a confluência entre Estado, empresas construtoras e capital financeiro. Belo Horizonte: C/Arte, 2012.

SILVA, M. da G. P. A "irregularidade" na produção de conjuntos habitacionais de interesse social. In: XI ENCONTRO NACIONAL DA ASSOCIAÇÃO NACIONAL DE PÓS-GRADUAÇÃO E PESQUISA EM PLANEJAMENTO URBANO E REGIONAL. Anais [...]. Salvador: Anpur, 2005.

SINGER, P. Economia política da urbanização. São Paulo: Contexto, 1973.

SMDU, Secretaria Municipal de Desenvolvimento Urbano. Censo da população por distrito. Disponível em: http://smul.prefeitura.sp.gov.br/historico_demografico/tabelas.php. Acesso em: 10 set. 2020.

SMITH, N. Gentrificação, a fronteira e a reestruturação do espaço urbano. In: Revista GEOUSP, São Paulo, n. 21, p. 15-31, 2007.

VOLOCHKO, D. Novos espaços e cotidianos desiguais nas periferias da metrópole. 2011. (Tese de Doutorado) - Faculdade de Filosofia, Letras e Ciências Humanas, Universidade de São Paulo, São Paulo, 2011. 


\section{Carolina Alvim de Oliveira Freitas}

Doutoranda na área de Habitat pela Faculdade de Arquitetura e Urbanismo da Universidade de São Paulo. Mestra em Planejamento Urbano e Regional pela mesma faculdade, autora da dissertação Mulheres e periferias como fronteiras: o tempo-espaço das moradoras do Conjunto Habitacional José Bonifácio, que obteve menção honrosa no XI Prêmio Brasileiro Política e Planejamento Urbano e Regional pela Anpur, 2019.

Email: carolinaaof@gmail.com

ORCID: 0000-0003-0961-911X

Submissão: 20 de abril de 2020.

Aprovação: 21 de agosto de 2020 .

Como citar: FREITAS, C. A. de O. Transformações na produção da periferia: o caso de Itaquera e o Conjunto Habitacional José Bonifácio. Revista brasileira de estudos urbanos e regionais. v. 22, E202028, 2020. DOI 10.22296/2317-1529.rbeur.202028

Artigo licenciado sob Licença Creative Commons CC BY-NC 4.0.

https://creativecommons.org/licenses/by-nc/4.o/deed.pt_BR 